Article

\title{
Effect of Chloride on Electrical Resistivity in Carbonated and Non-Carbonated Concrete
}

\author{
In-Seok Yoon ${ }^{1, *}$ and Chun-Ho Chang ${ }^{2}$ \\ 1 Construction Information Engineering, Induk University, Seoul 01878, Korea \\ 2 Civil Engineering, Keimyung University, Daegu 42601, Korea; chunho@kmu.ac.kr \\ * Correspondence: isyoon@induk.ac.kr; Tel.: +82-2-950-7585
}

Received: 20 August 2020; Accepted: 8 September 2020; Published: 9 September 2020

\begin{abstract}
The resistivity of a concrete structure exposed to chloride ions indicates the risk of early corrosion damage, because a low resistivity is related to rapid chloride penetration and to a high corrosion rate. Concrete resistivity is a geometry-independent material property that describes the electrical resistance, which is the ratio between the applied voltage and resulting current in a unit cell. The current is carried by ions dissolved in the pore liquid. While some data exist on the relationship between the moisture content and electrical resistivity of concrete, very little research has been conducted to evaluate the effect of chloride on the conduction of electricity through carbonated and non-carbonated concrete. The purpose of this study is to examine the effect of chloride concentration on the surface electrical resistivity measurement of carbonated and non-carbonated concrete. Chloride concentration had influenced the resistivity of concrete and the relationship showed a linear function. However, for concrete under the combined deterioration of carbonation and chlorides, a reduction in porosity due to the carbonation had a greater effect on the electrical resistivity than the increase in conductivity due to the chloride ions. Conclusively, this paper suggested the quantitative solution to depict the electrical resistivity of concrete with various chloride concentrations.
\end{abstract}

Keywords: electrical resistivity; chloride; carbonation; combined deterioration

\section{Introduction}

Electrical conductivity is a measure of how well a material accommodates the movement of an electric charge. It is the ratio of the current density to the electric field strength. Electrical resistivity is the reciprocal of conductivity. It is the is the opposition of a body or substance to the flow of an electrical current through it, resulting in a change of electrical energy into heat, light, or other forms of energy.

Electrical resistivity in concrete is a reversed function of conductivity and is related to the diffusivity of ions in the pores [1]. The measurement of electrical resistivity is considered to be a very attractive method for evaluating the properties of geomaterials and for the quality control of concrete because such non-destructive testing (NDT) is simple, rapid, and cost-effective [2]. Particularly, electrical resistivity can be classified into two stages of durability, as proposed by Tuutti [3], which are before and after steel corrosion and thus can be used as the barometer of durability during the latent period relating to the micro structure of the concrete as well as the corrosion progress period [4-6]. Electrical resistivity measurements as NDT in the concrete industry are employed for the following reasons: (i) to measure resistivity without damage; (ii) to save time and costs; and (iii) to obtain the results of the measurements in real time. Figure 1 shows the classification of the service life of a concrete structure into stages: (i) the initiation period; and (ii) the propagation period. In general, the initiation and propagation periods are strongly dominated by the chloride diffusivity and corrosion current density of the reinforcement, respectively, both of which are qualitative indices. However, these experimental 
data are not easy to obtain on site. As an alternative to these two indices, electrical resistivity can be measured relatively easily and used as a qualitative index for evaluating the corrosion rate of concrete and eventually predicting its service life [7-9]. Nevertheless, electrical resistivity measurements have many factors causing data interference. The chloride and water content in concrete may also have an effect on electrical resistivity [10]. Even so, electrical resistivity has some disadvantages because it is affected by several other factors, e.g., (i) the amount of cement paste; (ii) a water-cementitious material ratio; (iii) curing condition; (iv) exposure temperature; (v) chlorides; (vi) moisture content; (vii) cement type, and the volumetric fraction of the cement paste; (viii) type and amount of admixtures; and (ix) quality and volumetric fraction of the aggregate [9]. When a current is applied, the electric field is dependent on the chloride concentration that has an effect on the pore water transfer [11,12], and thus it is necessary to monitor the data on the change in electrical resistivity of concrete containing various chloride concentrations over time.

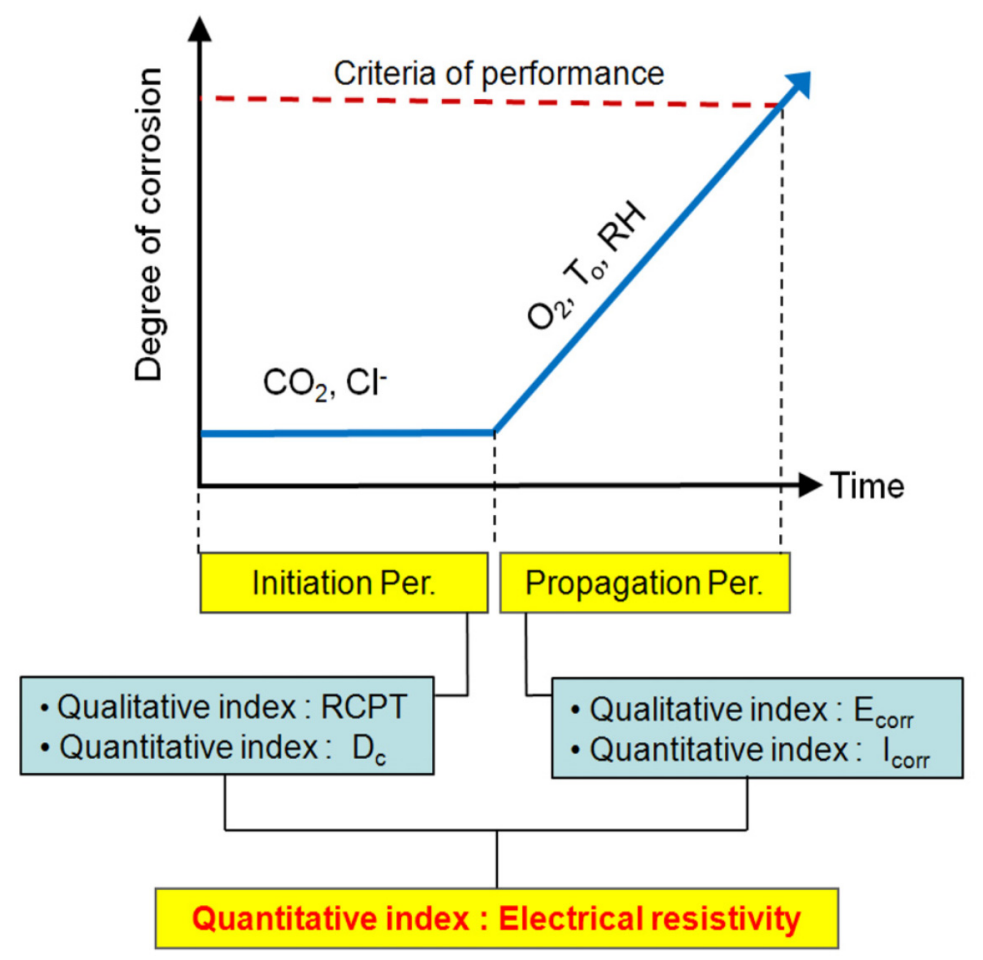

Figure 1. Modified schematic sketch of the steel corrosion sequence in concrete (updated from [3]).

Meanwhile, the electrical conductivity is not caused by the binding of electrons in an electrolyte solution but depends on the movement of charges. The resistance of the electrolyte solution is highly dependent on the concentration, while distilled water is generally an insulator and seawater is considered a high conductor. Therefore, when the chloride concentration increase, the electrical resistivity should decrease [13]. The decrease in resistivity between subsequent intervals of increasing chloride concentration decreased as the moisture content increased [14]. Since resistivity is measured by applying a current through the concrete and a potential difference is measured, increasing the chloride concentration of the pore water solution will improve the current conduction as ions help carry the current [15]. Nevertheless, it is rare to study the change in the electrical resistivity of concrete due to the effect of the chloride ions and carbonation. Because of the electrical nature of the resistivity measurements, the presence of ions within the section of concrete to be tested should affect the results. Because the electrical resistivity is closely related to the porosity of the concrete, it is possible to judge the resistance to chloride penetration, as shown in Table 1. Electrical resistivity is well correlated with certain performance characteristics of concrete, such as the chloride diffusivity, water absorption, and corrosion rate of the embedded steel. The technique also shows promise as a quality assurance tool for fresh and hardened concrete, 
as shown in Table 2. It is also a function of the concentration of the ions and their mobility in the pore solution $[16,17]$. However, only the correlation between the durability criteria and electrical resistance was presented in terms of chloride penetration, and the change in electrical resistivity due to the presence of the chloride ions in carbonated or non-carbonated concrete was not illustrated.

Table 1. Chloride ions penetrability.

\begin{tabular}{|c|c|c|c|}
\hline \multirow{2}{*}{$\begin{array}{l}\text { Chloride Ion } \\
\text { Penetrability }\end{array}$} & AASHTO TP 95 [1] & AASHTO T358-15 [18] & \multirow{2}{*}{ Thomas [19] } \\
\hline & $100 \mathrm{~mm} \times 200 \mathrm{~mm}$ Cylinder $(\mathrm{K} \Omega \cdot \mathrm{cm})$ & $150 \mathrm{~mm} \times 300 \mathrm{~mm}$ Cylinder $(\mathrm{K} \Omega \cdot \mathrm{cm})$ & \\
\hline High & $<12$ & $<9.5$ & $<5$ \\
\hline Moderate & $12 \sim 21$ & $9.5 \sim 16.5$ & $5 \sim 10$ \\
\hline Low & $21 \sim 37$ & $16.5 \sim 29$ & $10 \sim 20$ \\
\hline Very low & $37 \sim 254$ & 29 199 & $20 \sim 200$ \\
\hline Negligible & $>254$ & $>199$ & $>200$ \\
\hline
\end{tabular}

Table 2. Comparison of chloride penetrability levels established for standards based on electrical resistivity (AASHTO TP 95) and charged passed (ASTM C 1202).

\begin{tabular}{ccc}
\hline Chloride Ion Penetrability & AASHTO TP 95 [1] $\mathbf{( K \Omega \cdot c m )}$ & ASTM C 1202 [20] (Coulombs) \\
\hline High & $<12$ & $>4000$ \\
\hline Moderate & $12 \sim 21$ & $2000 \sim 4000$ \\
\hline Low & $21 \sim 37$ & $1000 \sim 2000$ \\
\hline Very low & $37 \sim 254$ & $100 \sim 1000$ \\
\hline Negligible & $>254$ & $<100$ \\
\hline
\end{tabular}

This paper is intended to evaluate the variation characteristics of the electrical resistivity, depending on the chloride concentration, for carbonated and non-carbonated concrete. Many structures are deteriorated by chloride or the combined deterioration by carbonation and chlorides, and this mechanism is very complicated, as shown in Figure 2. The variation in electrical resistivity was examined over time after mixing chloride ions in the concrete with various $w / c$ ratios and after carbonation in the concrete with chloride ions. Therefore, electrical resistivity still can be useful even after the concrete is deteriorated by carbonation and chloride penetration.

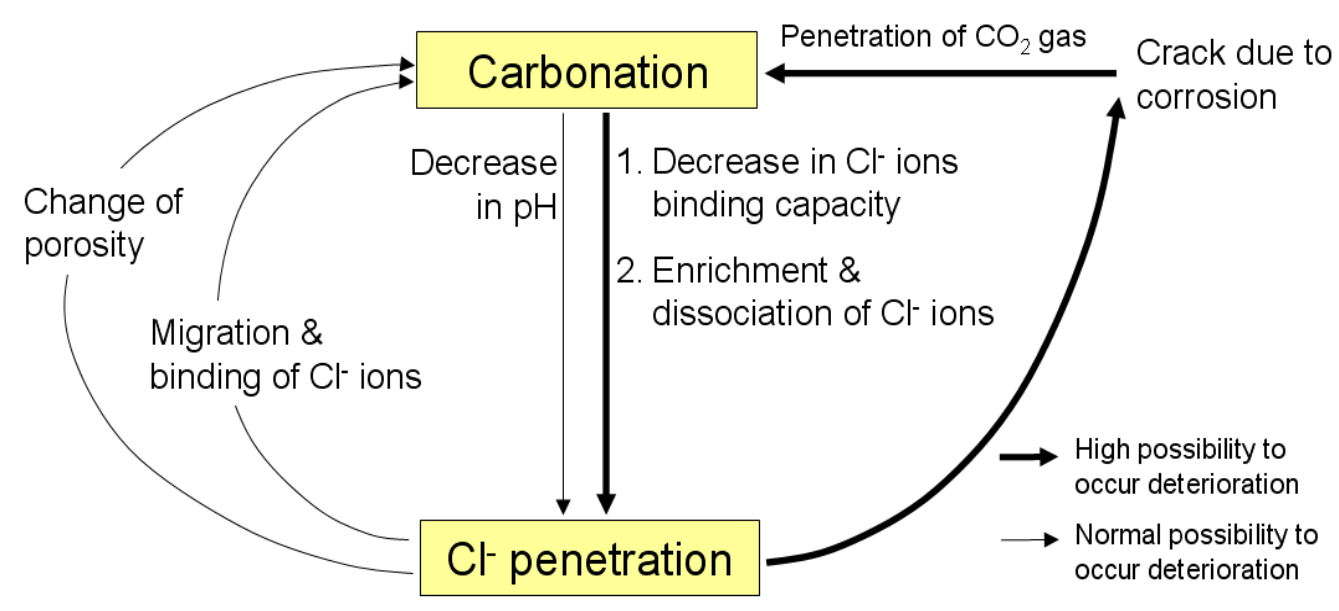

Figure 2. Mechanism of interaction between carbonation and chloride penetration [21]. 


\section{Experiment Program}

\subsection{Preperation of Samples}

Commercial cement, Type I KS L 5201 Ordinary Portland Cement (OPC), was used with a water-cement ratio $(w / c)$ of $0.45,0.50$, and 0.55 , as shown in Table 3. For the chloride-contaminated specimen, sodium chloride was mixed with mixing water, $0 \%, 0.5 \%, 1.0 \%, 1.5 \%$, and $2.0 \%$ by weight of cement. The specimen was submerged in the same saltwater as the sodium chloride-mixed water used when producing the initial specimen till measuring. The size of each specimen was determined to be $100 \mathrm{~mm}(\mathrm{~L}) \times 100 \mathrm{~mm}$ $(\mathrm{W}) \times 200 \mathrm{~mm}(\mathrm{H})$, such that the spacing of the electrodes was much smaller than the height of the materials. The curing temperature was $20^{\circ} \mathrm{C}$. After 28 days of water curing, followed three different curing conditions, i.e., (1) air-dry; (2) water curing; (3) pre-mixed chloride; and (4) combined deterioration due to carbonation and chloride ions. Testing with the three types of conditions was intended to investigate the change in electrical resistivity due to the water content and chloride concentration.

Table 3. Mixing proportion of the concrete.

\begin{tabular}{ccccc}
\hline \multirow{2}{*}{$w / c$} & \multicolumn{4}{c}{ Unit Weight $\left(\mathbf{k g} / \mathbf{m}^{\mathbf{3}}\right)$} \\
\cline { 2 - 5 } & Water & Cement & Sand & Gravel \\
\hline 0.45 & 185 & 411 & 706 & 1001 \\
\hline 0.50 & 185 & 370 & 720 & 1021 \\
\hline 0.55 & 185 & 336 & 732 & 1038 \\
\hline
\end{tabular}

\subsection{Carbonation of Concrete}

For the combined deterioration experiment due to carbonation and chloride, a concrete specimen with chloride of $1.0 \%, 2.0 \%$ by weight of cement, was exposed to an accelerating carbonation chamber. The concrete specimens were placed in a chamber with a controlled $\mathrm{CO}_{2}$ concentration of $5 \%$ at a temperature of $20^{\circ} \mathrm{C}$, and a relative humidity of $65 \%$. A phenolphthalein indicator was applied on the fresh fractured surfaces of the specimens to measure the carbonation depth.

\subsection{Measurment of Electrical Resistivity}

It is important to prepare the specimen with the same conditions before testing because the electrical resistivity of concrete is significantly sensitive to moisture. The four-electrode method, known as the Wenner four-pin method, was developed initially for conducting soil resistivity tests by the U.S. Bureau of Standards.

A four-pin resistivity meter was used to measure the electrical resistivity of the concrete specimens (Figure 3). The measurement was based on ASTM C1760-12 [22]. For each specimen, four separate measurements were made on four different surfaces. Electrical resistivity is in reverse proportion to the current applied $(I)$ and the potential difference $(V)$ is measured on an electrode inside; the apparent electrical resistivity is measured by the following equation according to Ohms law:

$$
\rho=\frac{2 \pi a V}{I}
$$

where $\rho$ is the electrical resistivity of the concrete, $a$ is interval between the electrodes. 


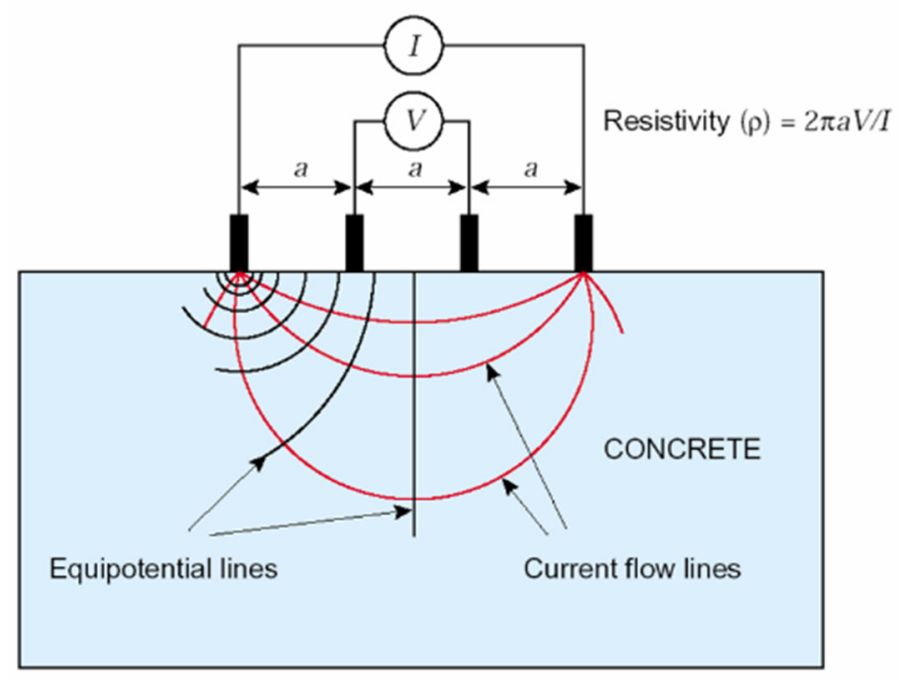

Figure 3. Measurement of the electrical resistivity measurements in concrete.

\section{Results and Discussion}

\subsection{Effect of the Age of Samples}

Figure 4 describes the electrical resistivity measurements of a saturated specimen over a period of time. A gradual increase in electrical resistivity was observed for the greater age of the specimen.

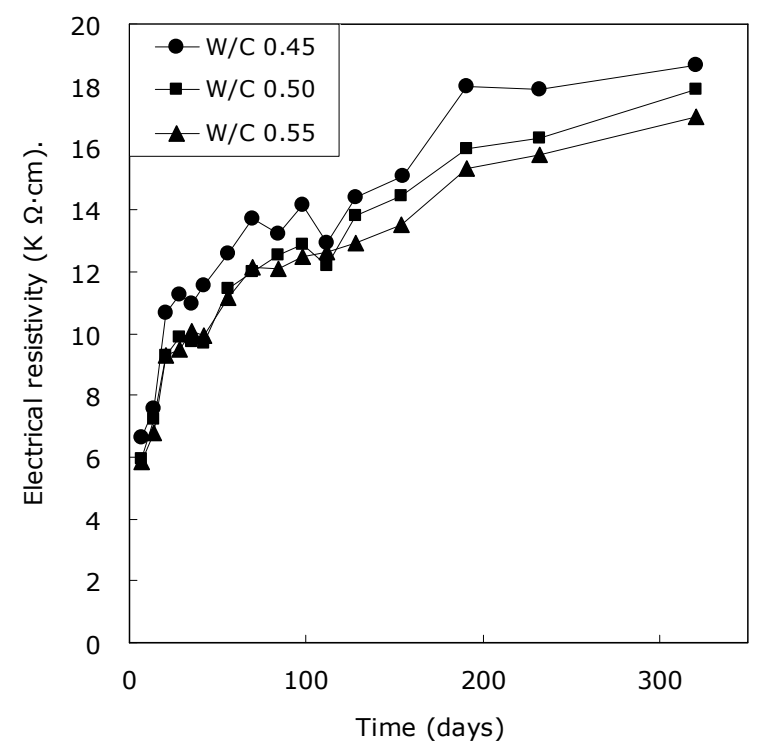

Figure 4. Electrical resistivity measurements of the saturated concrete without chloride.

At an early age, there are no differences in the electrical measurements among the different pastes, but it was observed that the mixture that had the lowest $w / c$ ratio had the highest electrical resistivity at the end of the experiments. The primary reason should be that the paste that has the lowest $w / c$ ratio has more hydration products and less porosity than the other two mixtures.

Figure 5 shows the measurements of the electrical resistivity of the air-dried concrete. Until 100 days of air-dried curing, it was observed that the resistivity increased gradually as the age increased. However, the electrical resistivity increased dramatically from an age of 100 days to the completion of the experiment. The electrical resistivity measurement at the end of the experiment was approximately $1400 \mathrm{~K} \Omega \cdot \mathrm{cm}$. According to the guideline value provided by RESI (2002), corrosion is very low if the electrical resistivity 
is greater than $12 \mathrm{~K} \Omega \cdot \mathrm{cm}$. Therefore, it is expected that the environment for anti-corrosion is driven after 70 days of air-dried and saturated curing.

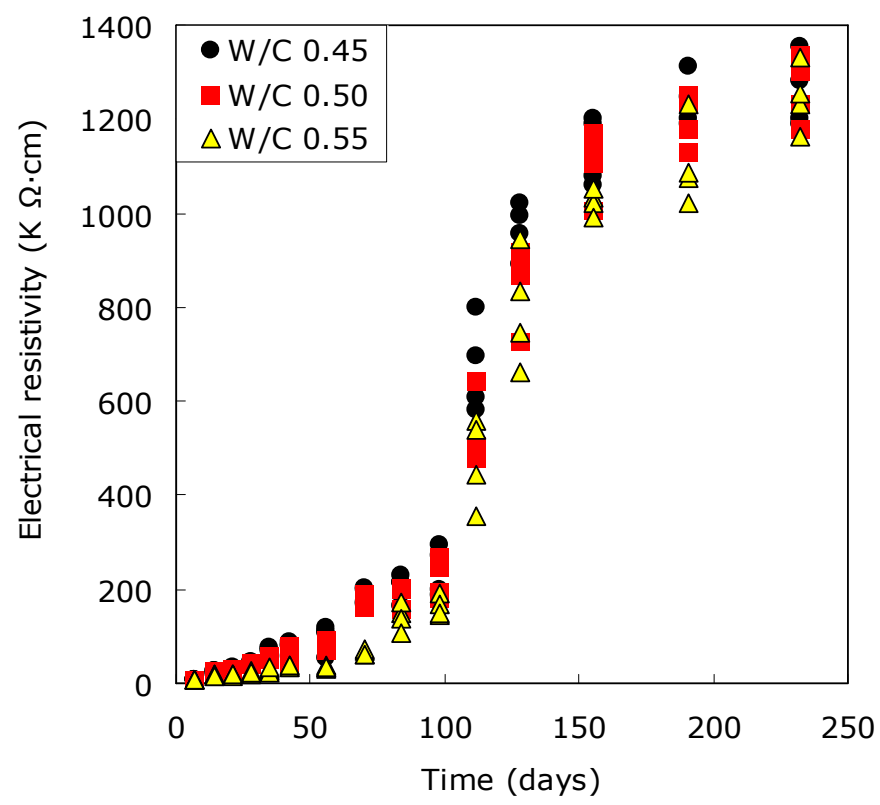

Figure 5. Electrical resistivity measurements of the air-dried concrete without chloride.

\subsection{Effect of the Pore Water of Concrete}

Moisture within the concrete's pores is essential for the passage of electrical current, through which resistivity can be determined. Lowering the moisture content will restrict the current flow and will consequently increase the measured resistivity. For this reason, the measurement of electrical resistivity is strongly influenced by the amount of water in the materials (Figure 6). According to Buenfeld et al. [4] and Goni and Andrade [10], the electrical resistivity of water in the pores is about $5 \times 10^{-2} \mathrm{~K} \Omega \cdot \mathrm{cm}$. According to Yoon's experimental results [23], completely dried concrete does not allow ions or charges to move. Therefore, the small amount of pore water in concrete can lead to high conductivity and low resistivity.

Figure 7 shows the relationship between the electrical resistivity and the volumetric fraction of the capillary pore water of the specimens. The amount of capillary water in the pores was estimated by the cement hydration model proposed by van Breugel [24]. The maximum volumetric fraction of the capillary pore water was approximately 0.6 and the ratio of the electrical resistivity of the air-dried concrete to that of the saturated concrete decreased dramatically as the amount of pore water increased. The relationship between the electrical resistivity ratio of the concrete and the volumetric fraction of the capillary water in the pores is expressed in Equation.

In particular, the electrical resistivity ratio of air-dried to saturated concrete is very sensitive to the amount of capillary water in the pores. A sudden decrease in the resistivity ratio from 0.3 to 0.45 was observed. However, a gradual decrease of the ratio of air-dried to saturated concrete was observed as a function of the volumetric fraction of the capillary water in the pores between 0.45 and 0.6. From these observations, it can be concluded that the capillary pore water in concrete significantly influences its electrical resistivity and its relationship can be expressed as follows:

$$
\rho_{\text {air }}=1.822 \times 10^{4} \exp \left[-17.079\left(\frac{V_{\text {water }}}{V_{\text {pore }}}\right)\right] \cdot \rho_{\text {sat }}
$$




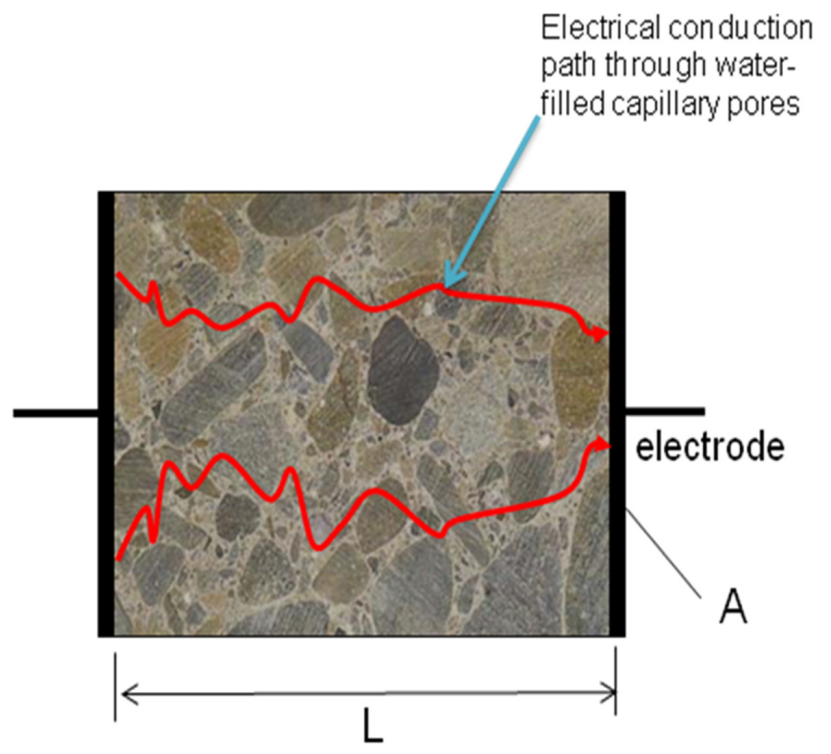

Figure 6. Effect of pore water on the electrical resistivity of concrete.

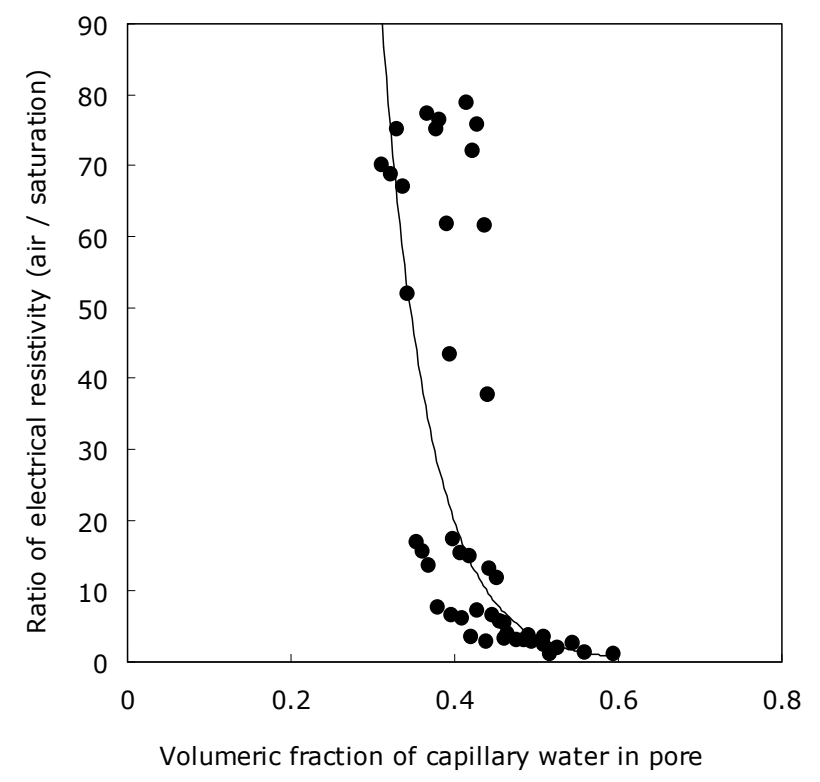

Figure 7. Relationship between the electrical resistivity of the concrete and the volumetric fraction of the capillary water in the pores.

\subsection{Effect of Chloride Concentration}

Figure 8 represents the variation in electrical resistivity of the concrete, depending on chloride concentration. The electrical resistivity continued rising due to the generation of hydrates and a pore structure in line with increasing hydration over time. At the early stage, concrete has a low electrical resistivity. As the microstructure of the concrete was developed with elapsed time, however, the electrical resistivity tended to increase. The trend was obvious depending on the chloride concentration. The higher the chloride concentration, the less the electrical resistivity. According to the RESI-specific resistance measurement standard and Broomfield [25], the risk of reinforcement corrosion is extremely low when its $12 \mathrm{~K} \Omega \cdot \mathrm{cm}$ or $20 \mathrm{~K} \Omega \cdot \mathrm{cm}$. The common value of the two suggestions was $12 \mathrm{~K} \Omega \cdot \mathrm{cm}$. All concrete, excluding the specimen with chloride ions of $2.0 \%$ and a $w / c$ ratio of 0.55 , failed to meet the value. According to Liu et al. [9], the electrical resistivity of concrete containing $2 \%$ chloride ions in weight 
was reportedly reduced by the level of 50 60\%. The effect of chloride ions on the electrical resistivity of concrete may be considerable because of dry and wetting of the salt water. This study showed that the specimen with $2.0 \%$ chloride ions was $65 \sim 71 \%$ of the concrete without chloride ions and the variation with the $w / c$ ratio was not noticed.

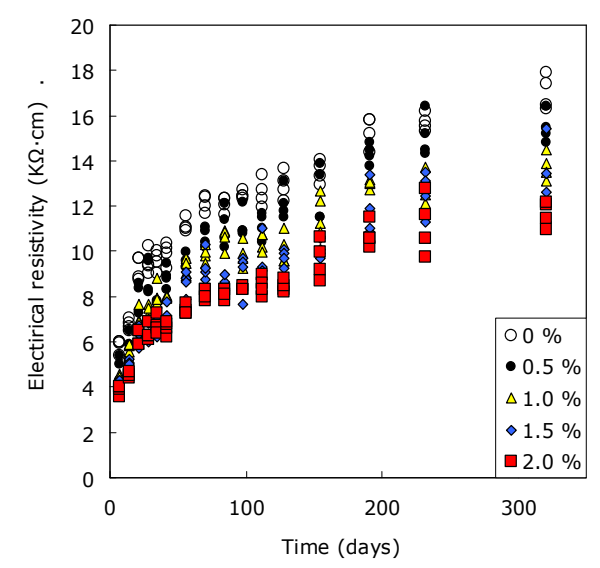

(a) $w / c 0.45$

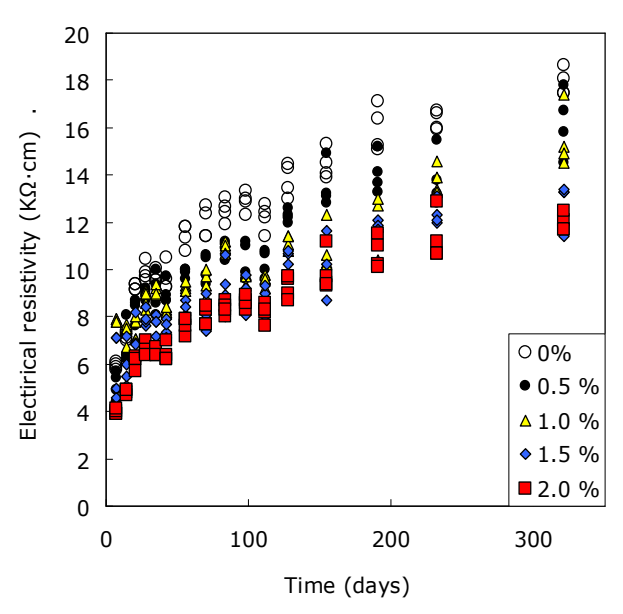

(b) $w / c 0.50$

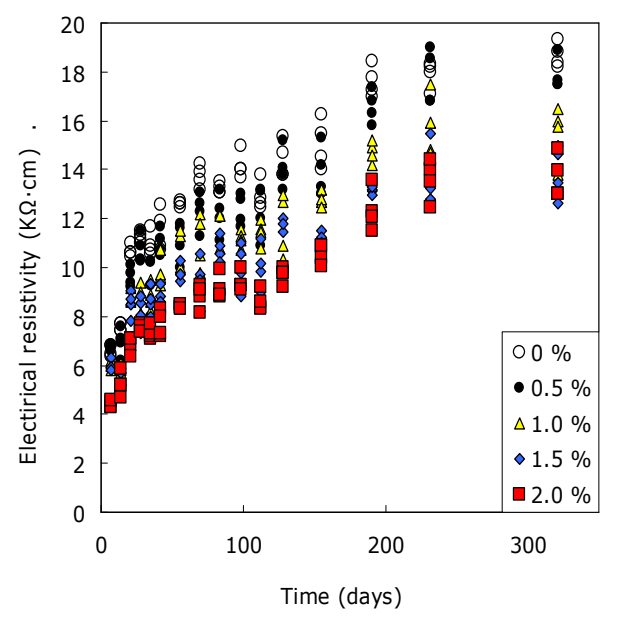

(c) $w / c 0.55$

Figure 8. Electrical resistivity of the concrete with chloride concentration. 


\subsection{Effect of Chloride Ions with Time}

Figure 9 shows the variation of determinant coefficient as a result of the linear regression analysis of the electrical resistivity ratio vs. the chloride concentration over time. Though the accuracy was not high, the correlation between the chloride concentration and the ratio of electrical resistivity ratio exceeded 0.70, which means the obvious effect of chloride ion on electrical resistivity. At the early stage of concrete curing, the determinant coefficient was low and then increased over time; however, the effect with the $w / c$ ratio was not clear. A low determinant coefficient seemed to be attributable to the irregular variation in electrical resistivity of concrete with chloride concentration when the hydration of the concrete was not activated in earnest during the early time.

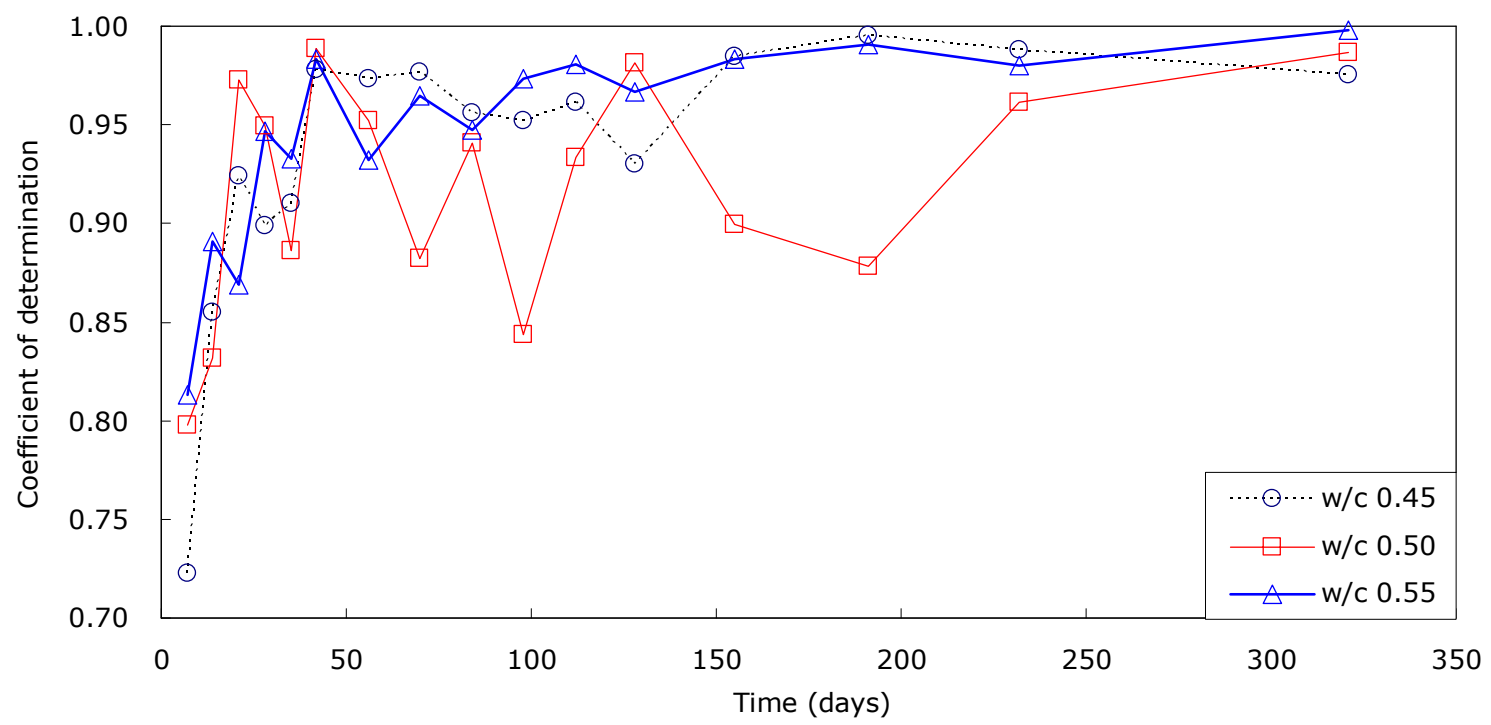

Figure 9. Coefficient of determination in the linear regression deriving from the resistivity ratio vs. chloride concentration.

Figure 10 shows the incline of the linear regression analysis equation of the electrical resistivity ratio and chloride concentration with the concrete without chloride concentration. The gradient of the linear regression analysis equation was low during the early time; however, it was constant without significant variation from 50 days onwards. That is, a decrease in the electrical resistivity depending on chloride concentration was rather low till 50 days and then continued to rise. After 50 days, the trend could not be examined. The electrical resistivity of concrete vs. chloride concentration was insignificant after 50 days and this was attributable to two reasons. First, the C-S-H phase and AFm phase, which can react with water-soluble chloride to form bound chloride, are not well developed [26]. At the early stage, chloride adsorption is not active because of immature development of the two hydrates. In addition, it is known that chloride can reduce the electrical resistivity of water. Secondly, chloride can be a cause of the change of the micro-structural characteristics of cementitious materials. In general, sodium chloride increases the $\mathrm{pH}$ of the pore solution in concrete and increase in alkali content, which causes a heterogeneous C-S-H phase [27]. Therefore, chloride leads to capillary porosity with a large pore space and this can be a cause of the low electrical resistivity of concrete. The first reason of chloride ion absorption and the second reason of micro-structure on the electrical resistivity of concrete are not consistent. The micro-structure of hardened cementitious material has a greater influence on electrical resistivity than chloride absorption; however, consider the low gradient at the early stage and its increase with time. 


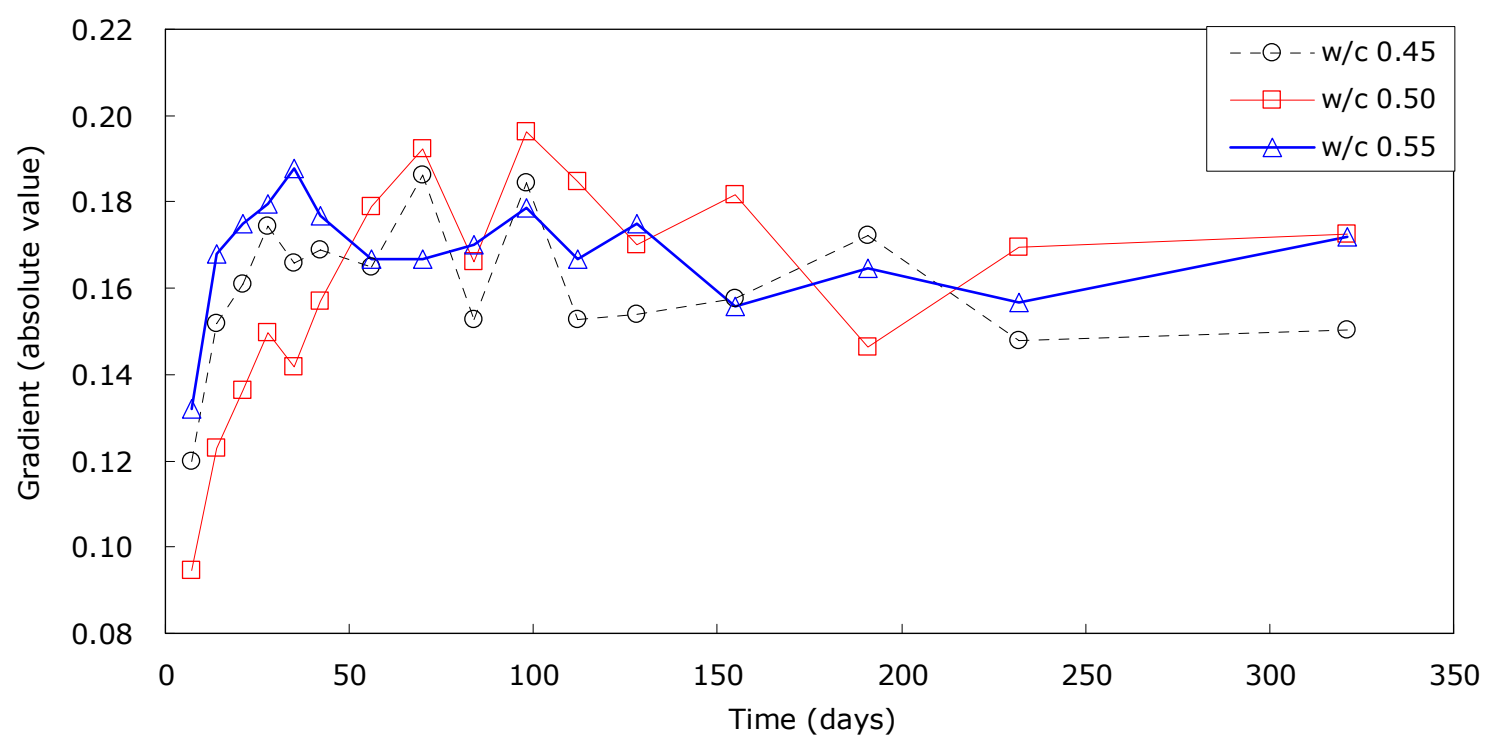

Figure 10. Gradient in the linear regression deriving from the resistivity ratio vs. chloride concentration.

\subsection{Effect of Chloride Ions on Electirical Resisitvity}

Figure 11 represents the variation in electrical resistivity depending on chloride concentration. In the figure, the $Y$ label, the electrical resistivity ratio between the concrete with chloride and concrete without chloride, was calculated from Figure 8 . The variation in electrical resistivity of the concrete with the $w / c$ ratio was not monitored; however, the electrical resistivity had decreased for concrete with a high chloride concentration.

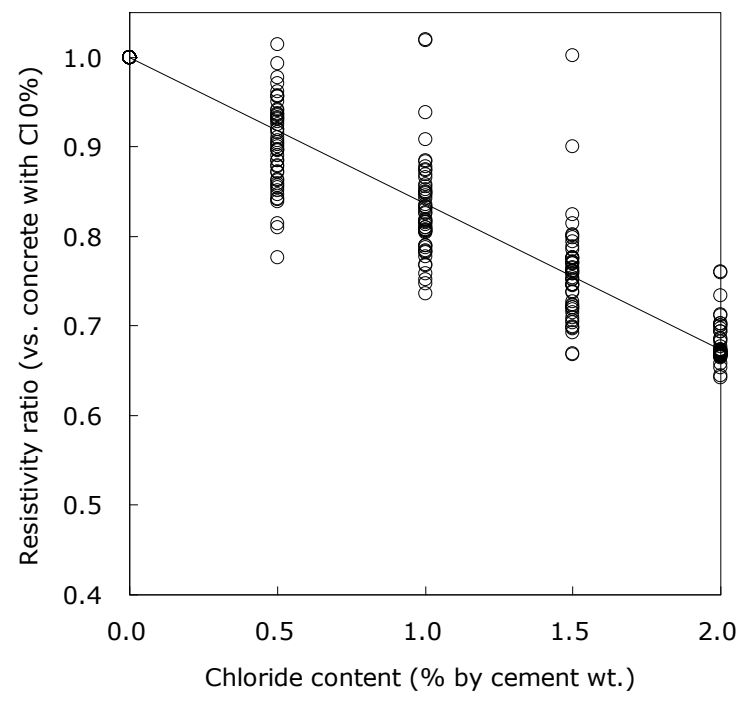

Figure 11. Chloride concentration vs. resistivity of the concrete.

Based on the Figure 11, the average electrical resistivity of concrete contaminated with the same chloride concentration was calculated. Figure 12 shows the correlation between the chloride concentration and ratio of the average electrical resistivity of concrete with chloride concentration. The variation with the $w / c$ ratio was not monitored. It is obvious that the chloride concentration leads 
to reduced resistivity of the concrete. The determinant coefficient was 0.97 , which is meaningful in determining the variation in electrical resistivity of concrete with chloride ion content, as follows:

$$
\frac{\rho_{C l}}{\rho_{\text {wat }}}=1-0.163 C_{C l}
$$

where $\rho_{C l}$ is the electrical resistivity of the concrete with chloride ions; $\rho_{w a t}$ is the electrical resistivity of the concrete without chloride ions, $C_{C l}$ is the chloride ion in the concrete (by weight of the cement).

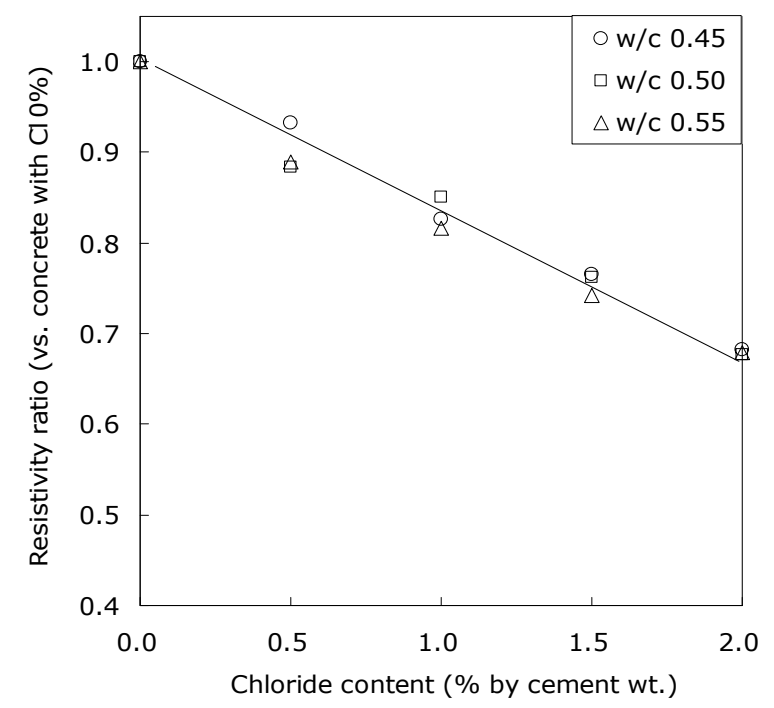

Figure 12. Effect of chloride concentration on the resistivity of concrete.

Figure 13 represents the result of measuring the carbonation depth of concrete mixed with chloride ions. The higher the chloride ion, the higher the carbonation depth. This trend was more evident for concrete with a high $w / c$ ratio.

Figure 14 shows the average value of the electrical resistivity of the carbonated concrete mixed with chloride ions and a clear experimental trend was not observed. Although concrete without chloride ions should show a higher electrical resistivity than concrete with chloride ions at the beginning, the opposite trend was noticed as time elapsed. Electrical conductivity is decreased by carbonation, revealing the complex nature of the microstructure change [28], while the chloride-binding capacity is decreased due to consumption of the chloride adsorbent, C-S-H phase, and Friedel's salt [29]. These two have mutually contradictory effects on the electrical resistivity of carbonated concrete. At the early stage, the effect of carbonation on resistivity is not significant, thus the electrical resistivity decreases because of only the influence of the chloride ions on the electrical conductivity. However, it showed a somewhat opposite trend as time elapsed. This means that electrical resistivity should be influenced by carbonation with elapsed time because of the reduction in porosity [30]. In particular, because the bound chlorides can be converted into water-soluble chloride ions due to carbonation [31], electrical resistivity should be further lowered. Nevertheless, the opposite result was examined. It is believed, therefore, that the reduction in porosity due to carbonation has a greater effect on the electrical resistivity than the increase in conductivity due to chloride ions. 


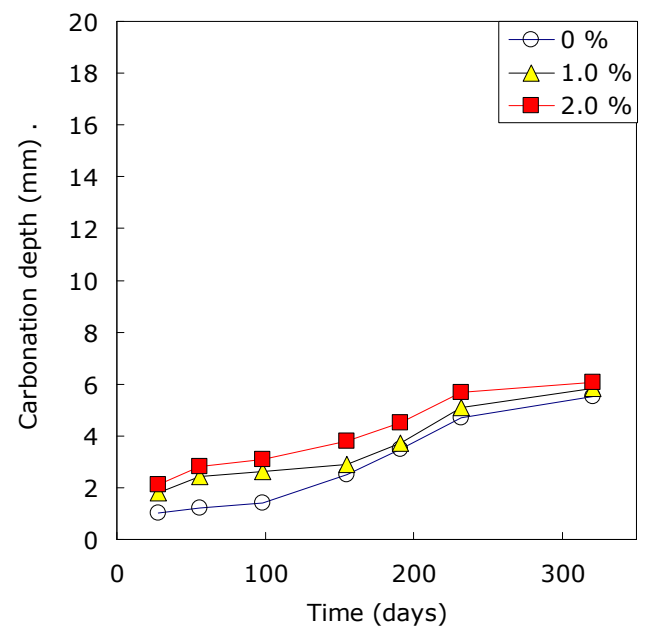

(a) $w / c 0.45$

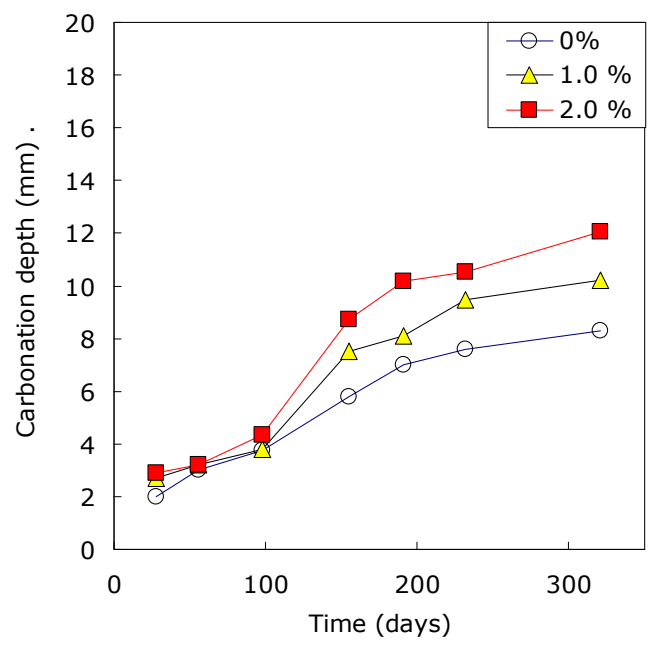

(b) $w / c 0.50$

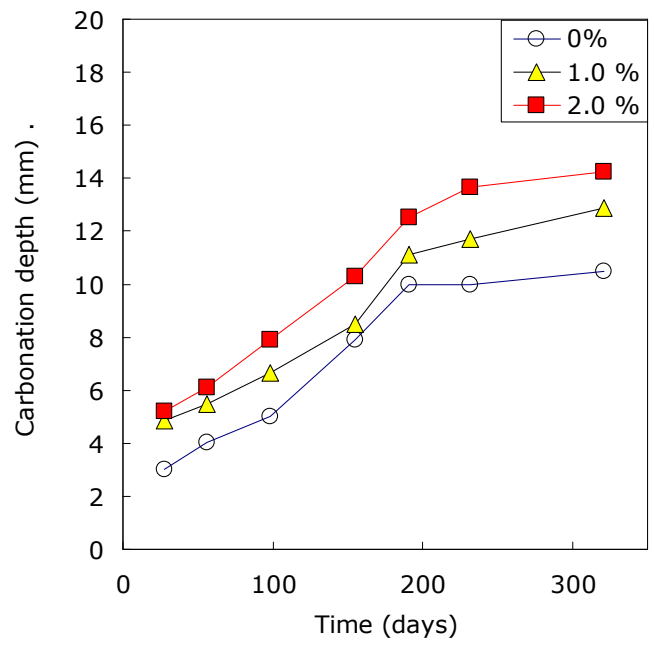

(c) $w / c 0.55$

Figure 13. Carbonation depth of the concrete with various chloride concentrations. 


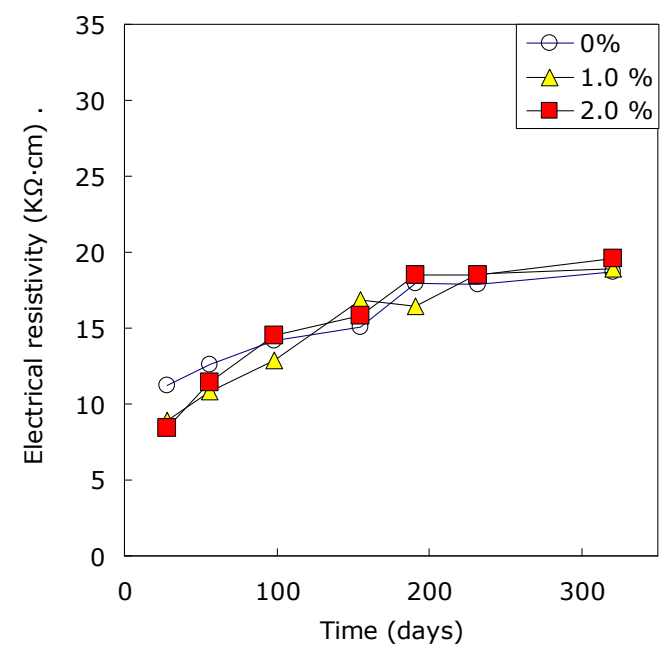

(a) $w / c 0.45$

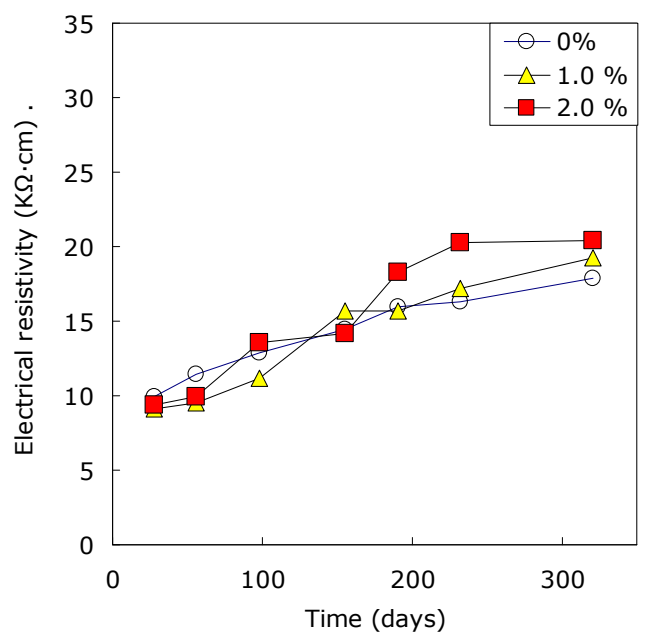

(b) $w / c 0.50$

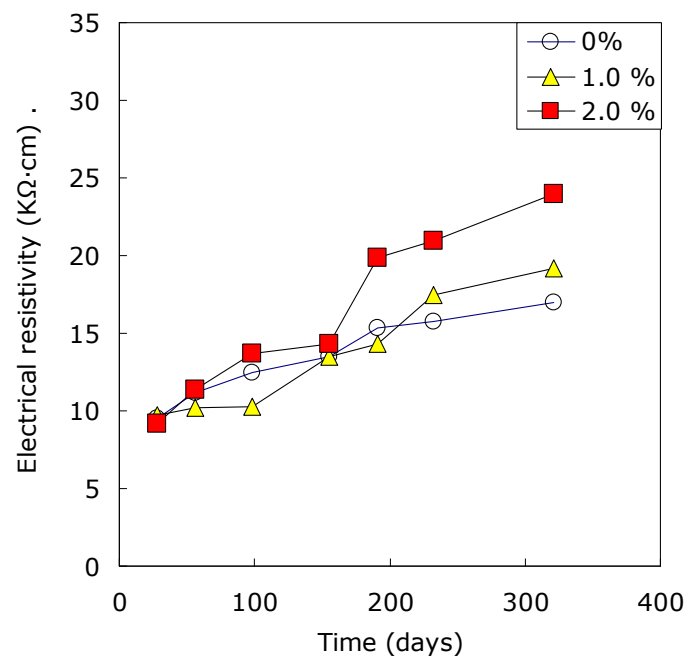

(c) $w / c 0.55$

Figure 14. Electrical resistivity of the carbonated concrete pre-mixed with chloride. 
Figure 15 shows the electrical resistivity ratio of the concrete under combined deterioration to normal concrete without carbonation and chloride ions. The $\mathrm{Y}$ label, the electrical resistivity ratio between the carbonated concrete and normal concrete, was calculated from Figure 14. The electrical resistivity ratio was clearly governed by the chloride concentration and carbonation depth. The higher the carbonation depth and the chloride concentration, the higher the electrical resistivity ratio. The ratio was 1.0 when the carbonation depth was about 5 to $8 \mathrm{~mm}$. This means that whether carbonation or chloride ions has a greater effect on the electrical resistivity of concrete should be determined at a carbonation depth of 5 to $8 \mathrm{~mm}$. The ratio of the electrical resistivity of the carbonated concrete $\left(\rho_{\text {comb }}\right)$ to that of non-carbonated concrete $\left(\rho_{\text {water }}\right)$ was derived by linear regression, as follows:

$$
\frac{\rho_{\text {comb }}}{\rho_{\text {water }}}=a \cdot x_{c}+b
$$

where $x_{c}$ is the carbonation depth $(\mathrm{mm}), a$ and $b$ are constants $(a=0.0187,0.0348$ for chloride $1.0 \%$, $2.0 \%$, respectively; $b=0.8547,0.8177$ for chloride $1.0 \%, 2.0 \%$, respectively).

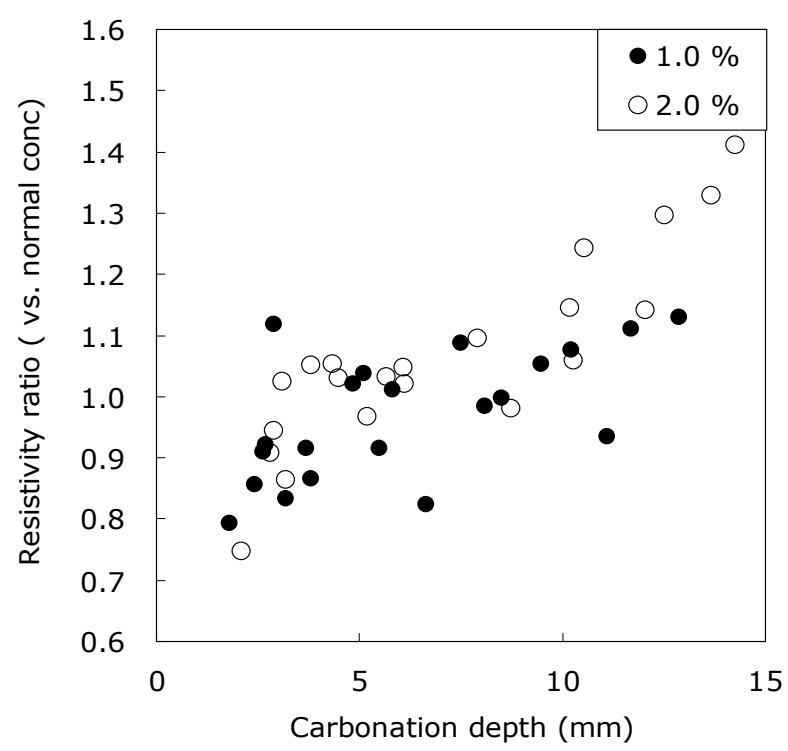

Figure 15. Ratio of the electrical resistivity of carbonated concrete with chloride of $1.0 \sim 2.0 \%$ and the electrical resistivity of non-carbonated concrete without chloride.

As shown in this study, a trend of the electrical resistivity of concrete under the combined deterioration of carbonation and chloride ions was not clear. Carbonation increases the electrical resistivity, while the chloride ions reduce the electrical resistivity. Therefore, when concrete is damaged by the combined deterioration of carbonation and chloride, the mutual interference effect causes collision, which depends on the carbonation depth, degree of contamination of the chloride, and the degree of hydration. In the future, it is necessary to investigate the mutual interference effect of the combined deterioration as hydration progresses.

\section{Conclusions}

The effects of chloride ions and carbonation on the electrical resistivity of concrete are different. The purpose of this study is to examine the effect of chloride concentration on the surface electrical resistivity measurement of carbonated and non-carbonated concrete. The interference effect was examined within the experimental scope of the study, and the results are summarized as follows: 
(1) Chloride concentration leads to reduced resistivity of the concrete. The electrical resistivity of the concrete kept rising over time and all concrete showed the value $12 \mathrm{~K} \Omega \cdot \mathrm{cm}$ or more, except the specimen with $2.0 \%$ chloride ions and a $w / c$ ratio of 0.55 . As a result of viewing the electrical resistivity rate, the value of the specimen with $2 \%$ chloride ions was $65 \sim 71 \%$ of the specimen without chloride ions.

(2) For the correlation between chloride ion content and electrical resistivity in the specimen without chloride ions, the correlation between chloride concentration and electrical resistivity exceeded the determination coefficient of 0.70 , indicating the obvious effect of chloride ions on electrical resistivity.

(3) The rate of change in the electrical resistivity of concrete with chloride was low in the early ages. However, the electrical resistivity showed a more stable trend with no change in the long-term age. These influences are generated by the adsorption of chloride ions and the micro-structure development of concrete due to on-going hydration of the cement. The micro-structure of the hardened cement paste has a greater influence on the electrical resistivity than chloride adsorption.

(4) The ratio of the electrical resistivity of concrete with chloride to that of concrete without chlorides decreased as the chloride concentration increased. The electrical resistivity of the concrete was significantly influenced by chloride concentration, even when the concentration was low.

(5) The electrical resistivity of concrete under combined deterioration tended to increase in proportion to the chloride concentration and carbonation depth. In the environment of a combined deterioration, the carbonation depth of 5 to $8 \mathrm{~mm}$ was a meaningful criterion for determining whether carbonation or chloride ions has a large effect on the electrical resistivity of concrete.

Author Contributions: I.-S.Y. conceived and designed the experiments; I.-S.Y. performed the experiments; I.-S.Y. and C.-H.C. analyzed the data; I.-S.Y. and C.-H.C. wrote the paper. All authors have read and agreed to the published version of the manuscript.

Funding: This research was supported by the Korea Basic Science Institute (National Research Facilities and Equipment Center) grant funded by the Korean Ministry of Education (grant No.2020R1A6C1020263).

Conflicts of Interest: The authors declare no conflict of interest.

\section{References}

1. AASHTO. AASHTO Designation TP 95, Standard Method of Test for Surface Resistivity of Concrete's Ability to Resist Chloride Ion Penetration; American Association of State Highway and Transportation Officials: Washington, DC, USA, 2011.

2. Ghosh, P.; Tran, Q. Correlation Between Bulk and Surface Resistivity of Concrete. Int. J. Concr. Struct. Mater. 2015, 9, 119-132. [CrossRef]

3. Tuutti, K. Corrosion of Steel in Concrete; Swedish Cement and Concrete Research Institute (CBI): Stockholm, Sweden, 1982.

4. Buenfeld, N.R.; Newman, J.B.; Page, C.L. The Resistivity of Mortar Immersed in Sea Water. Cem. Concr. Res. 1986, 16, 511-524. [CrossRef]

5. Hope, B.B.; Ip, A.K.; Manning, D.G. Corrosion and Electrical Impedance in Concrete. Cem. Concr. Res. 1985, 15, 525-534. [CrossRef]

6. Simon, G.; Tamas, K.; Vass, V. The Electrical Resistivity of Concrete, Concrete Structures. In Corrosion of Steel in Concrete; Tuutti, K., Ed.; Swedish Cement and Concrete Research Institute (CBI): Stockholm, Sweden, 2012; pp. 61-65.

7. Gjørv, O.E. Durability Design of Concrete Structures in Severe Environments; Taylor \& Francis: New York, NY, USA, 2009.

8. Altobat, S.; Maalej, M.; Shaikh, F.U.A. Laboratory Simulation of Corrosion Damage in Reinforced Concrete. Int. J. Concr. Struct. Mater. 2016, 17, 1-9. [CrossRef]

9. Liu, Y.; Suarez, A.; Presuel-Moreno, F.J. Final Report: Characterization of New and Old Concrete Structures Using Surface Resistivity Measurements; Florida Department of Transportation Research Center: Brooksville, FL, USA, 2010. 
10. Goni, S.; Andrade, C. Synthetic Concrete Pore Solution Chemistry and Rebar Corrosion Rate in the Presence of Chlorides. Cem. Concr. Res. 1990, 20, 525-539. [CrossRef]

11. Millard, S.G. Reinforced Concrete Resistivity Measurement Techniques. Proc. Civ. Eng. 1991, 91, 71-78. [CrossRef]

12. Millard, S.G.; Gowers, K.R. Resistivity Assessment of In-Situ Concrete: The Influence of Conductivity and Resistivity Layers. Proc. Civ. Eng. Struct. Build. 1992, 94, 389-395. [CrossRef]

13. Atkins, P.W.; De Paula, J. Physical Chemistry, 8th ed.; Oxford University Press: Oxford, UK, 2006.

14. Saleem, M.; Shameem, M.; Hussain, S.E.; Maslehuddin, M. Effect of Moisture, Chloride, and Sulphate Contamination on the Electrical Resistivity of Portland Cement Concrete. Constr. Build. Mater. 1996, 16, 209-214. [CrossRef]

15. Shaikhon, O. The Effect of Chloride and Sulfate Ions on the Resistivity of Concrete; McGill University: Montréal, QC, Canada, 2015.

16. Bertolini, L.; Polder, R.B. Concrete Resistivity and Reinforcement Corrosion Rate as Function of Temperature and Humidity of the Environment. In TNO Report 97-BT-R0574; TNO: The Hague, The Netherlands, 1997.

17. Bürchler, D.; Elsener, B.; Böhni, H. Electrical Resistivity and Dielectric Properties of Hardened Cement and Mortar; Institute of Materials Chemistry and Corrosion; Swiss Federal Institute of Technology; ETH Hönggerber: Zurich, Switzerland, 1996.

18. AASHTO. AASHTO T 358-17, Standard Method of Test for Surface Resistivity Indication of Concrete's Ability to Resist Chloride Ion Penetration; American Association of State Highway and Transportation Officials: Washington, DC, USA, 2017.

19. Thomas, R.J. Properties and Performance of Alkali-Activated Concrete. Ph.D. Thesis, Department of Civil Engineering, Clarkson University, Potsdam, NY, USA, 2016.

20. American Society of Testing and Materials. ASTM C1202-12, Standard Test Method for Electrical Indication of Concrete's Ability to Resist Chloride Ion Penetration; American Society of Testing and Materials: West Conshohocken, PA, USA, 2012.

21. JCI. Report: Committee on Investigation and Maintenance of Combined Deterioration of Concrete; JCI: St. Louis, MO, USA, 2001. (In Japanese)

22. American Society of Testing and Materials. ASTM C1760-12, Standard Test Method for Bulk Electrical Conductivity of Hardened Concrete; American Society of Testing and Materials: West Conshohocken, PA, USA, 2012.

23. Yoon, I.S. Influence of Micro-Structural Characteristics of Concrete on Electrical Resistivity. J. Korea Inst. Struct. Maint. Insp. 2013, 17, 122-129.

24. Van Breugel, K. Simulation of Hydration and Formation of Structures in Hardening Cement-Based Materials. Ph.D. Thesis, Delft University of Technology, Delft, The Netherlands, 1991.

25. Broomfield, J.P. Steel Corrosion in Concrete; E \& FN Spon: London, UK, 1997.

26. Yoon, I.S.; Saeki, T. Mechanism of Chloride Ion Adsorption in Cement Hydrates as Per the Time-Dependent Behavior. ACI Mater. J. 2020, accepted.

27. Dehwah, H.A.F.; Austin, S.A.; Maslehuddin, M. Effect of Cement Alkalinity on Pore Solution Chemistry and Chloride Induced Reinforcement Corrosion. ACI Mater. J. 2002, 99, 227-233.

28. Das, B.B.; Singh, D.N.; Pandey, S.P. Rapid Chloride Ion Permeability of OPC and PPC based carbonated concrete. J. Mater. Civ. Eng. 2012, 24, 606-611. [CrossRef]

29. Saillio, M.; Baroghel-Bouny, V.; Barberon, F. Chloride Binding in Sound and Carbonated Cementitious Materials. Constr. Build. Mater. 2014, 68, 82-91. [CrossRef]

30. Papadakis, V.G.; Vayenas, C.G.; Fardis, M.N. Fundamental Modeling and Experimental Investigation of Concrete Carbonation. ACI Mater. J. 1991, 88, 363-373.

31. Saeki, T.; Ueki, S.; Shima, T. A Model for Predicting the Deterioration of Concrete Due to the Compound Influence of Salt Damage and Carbonation. Proc. JSCE 2002, 54, 269-282.

(C) 2020 by the authors. Licensee MDPI, Basel, Switzerland. This article is an open access article distributed under the terms and conditions of the Creative Commons Attribution (CC BY) license (http://creativecommons.org/licenses/by/4.0/). 